\title{
Repeat-Induced Point Mutation (RIP) as an Alternative Mechanism of Evolution Toward Virulence in Leptosphaeria maculans
}

\author{
Isabelle Fudal, ${ }^{1}$ Simon Ross, ${ }^{1}$ Hortense Brun, ${ }^{2}$ Anne-Laure Besnard, ${ }^{2}$ Magali Ermel, ${ }^{2}$ Marie-Line Kuhn, ${ }^{1}$ \\ Marie-Hélène Balesdent, ${ }^{1}$ and Thierry Rouxel ${ }^{1}$ \\ ${ }^{1}$ INRA UMR 1290 BIOGER-CPP, F-78026 Versailles, France; '2UMR BIO3P, INRA, F- 35653 Le Rheu, France \\ Submitted 25 November 2008. Accepted 21 March 2009.
}

\begin{abstract}
Three avirulence genes, AvrLm1, AvrLm6, and AvrLm4-7, were recently identified in Leptosphaeria maculans and found to be localized as solo genes within large noncoding, heterochromatin-like regions mainly composed of retrotransposons, truncated and degenerated by repeat-induced point mutation (RIP). The Rlm6 resistance gene has been overcome within 3 years in outdoor experiments in France and, here, we investigate the molecular basis of evolution toward virulence at the AvrLm6 locus. A region of $235 \mathrm{~kb}$ was sequenced in a virulent isolate and showed the deletion of AvrLm6 and three divergent mosaics of retrotransposons. AvrLm6 was found to be absent from $66 \%$ of 70 virulent isolates, with multiple events of deletion. The sequencing of virulent alleles in 24 isolates revealed a few cases of point mutations that had created stop codons in the sequence. The most frequent mutation events, however, were RIP, leading to the modification of 4 to $9 \%$ of the bases compared with the avirulent allele and generating 2 to 4 stop codons. Thus, RIP is described for the first time as an efficient mechanism leading to virulence and the multiple patterns of mutation observed suggest that multiple RIP events could occur independently in a single field population during 1 year.
\end{abstract}

Plants have developed efficient defence systems to resist attacks by microbial pathogens. The plant immune response includes a basal level of pathogen recognition, the pathogenassociated molecular pattern (PAMP)-triggered immunity, which involves the recognition of common features of microbial pathogens (Zipfel and Felix 2005). Pathogens have evolved ways to escape this primary immune response through the delivery into the plant of pathogenicity effectors that suppress pathogen recognition (Chisholm et al. 2006). Then, plants developed a more specialized mechanism of pathogen detection that involves the recognition of effectors by resistance proteins directly or indirectly (Chisholm et al. 2006; Jones and Dangl 2006; Sacristan and Garcia-Arenal 2008). This specific recognition of the pathogen by its host plant is often controlled by a pathogen avirulence gene $(A V R)$ and a plant resistance gene $(R)$ as pro-

Corresponding author: Thierry Rouxel; E-mail: rouxel@versailles.inra.fr

The sequences analyzed in this study have been submitted to the EMBL databases under accession numbers CT485660 (v29-35C8), CT485652 (v29-55E6) and CT485654 (v29-51C1).

* The $\boldsymbol{e}$-Xtra logo stands for "electronic extra" and indicates that a supplemental table and a supplemental figure are published online. posed in the gene-for-gene model (Flor 1942), which usually triggers a rapid localized cell death, termed hypersensitive response (HR) that will stop pathogen infection (HammondKosack and Parker 2003). Pathogens can escape avirulencemediated host recognition by different molecular mechanisms, including nonsynonymous point mutations, frameshift mutations, deletion of the entire gene, or transposon insertion as exemplified for a few fungal plant pathogens (Catanzariti et al. 2006; Dodds et al. 2004; Farman et al. 2002; Gout et al. 2007; Joosten et al. 1997; Kang et al. 2001; Luderer et al. 2002; Orbach et al. 2000; Rep et al. 2004; Ridout et al. 2006; Schurch et al. 2004; Stergiopoulos et al. 2007; Westerink et al. 2004; Zhou et al. 2007). In addition, the genomic context can influence the potential of the avirulence genes to mutate. In the case of AVR-Pita, complete deletion of the gene was thought to be frequent as a consequence of its subtelomeric location (Orbach et al. 2000). Transposable elements can also alter avirulence-mediated host recognition by abolishing the $A V R$ gene expression (e.g., Pot 3 transposon insertion in the AVR-Pita promoter) (Kang et al. 2001) or by interrupting the avirulence gene (e.g., MINE retrotransposon insertion in the $A C E 1$ gene) (Fudal et al. 2005). Those mechanisms leading to virulence were mainly reported for laboratory mutants or collection isolates, and only a few large-scale molecular characterizations of virulent isolates were performed on natural populations of fungal plant pathogens in order to determine how virulent genotypes appear and disseminate (Gout et al. 2007; Schürch et al. 2004; Stergiopoulos et al. 2007).

Leptosphaeria maculans is responsible for one of the most devastating diseases of oilseed rape (OSR) (Brassica napus), called stem canker or blackleg. The fungus is present in most OSR-growing areas (Europe, North America, and Australia) (Fitt et al. 2006). Genetic studies demonstrated the occurrence of gene-for-gene interactions in the L. maculans-B. napus system where fungal avirulence ( $A v r L m)$ genes are the counterpart of plant resistance (Rlm) genes (Rouxel and Balesdent 2005). Currently, the use of resistant cultivars harboring single major resistance genes is the most cost-efficient method to control the disease when the corresponding avirulent allele (AvrLm) dominates in the pathogen population (Ansan-Melayah et al. 1997; Delourme et al. 2004). However, L. maculans displays a high evolutionary potential to overcome novel resistance sources, often only a few years after their commercial release. This was illustrated by the rapid "breakdown" of the commonly used $R l m l$ resistance in France in only 3 years concomitant to the drastic decrease of avirulent isolates in $\mathrm{L}$. $\mathrm{macu}$ lans populations, and the breakdown of the 'Surpass 400' resistance in Australia ( $\mathrm{Li}$ and Cowling 2003; Rouxel et al. 
2003a). Similarly, the Rlm6 resistance gene, currently absent from commercial cultivars, has been overcome within 3 years in France in experimental conditions (Brun et al. 2000). L. maculans is one of the few fungal pathogens for which avirulence genes have been cloned (Sacristan and Garcia-Arenal 2008), including AvrLm1 and AvrLm6, located in the same genetic cluster (Fudal et al. 2007; Gout et al. 2006). The genomic region spanning these two genes was sequenced and showed a particular isochore-like structure consisting of alternation of small (20 to $70 \mathrm{~kb}$ ) GC-equilibrated, open reading frame (ORF)-rich isochores intermingled with large (170 to 450 $\mathrm{kb}$ ) AT-rich isochores mainly composed of mosaics of truncated retrotransposons degenerated following repeat-induced point mutation (RIP) (Fudal et al. 2007; Gout et al. 2006). AvrLm1 and AvrLm6 share common characteristics: i) they encode small potentially secreted proteins (205 and 144 amino acids long, respectively) with no homology in the databases or in the L. maculans genome; ii) they are highly overexpressed during the primary leaf infection; and iii) they are present as solo genes within noncoding, heterochromatin-like regions of 269 and $133 \mathrm{~kb}$, respectively (Fudal et al. 2007; Gout et al. 2006). A large-scale study on the mechanisms leading to the inactivation of AvrLml in 460 L. maculans field isolates from France, Australia, and Mexico was recently performed by Gout and associates (2007) and showed that a unique, large deletion (260 kb) of a chromosomal fragment containing AvrLml was responsible for the switch to virulence in more than $90 \%$ of the cases. This major event was suggested to be influenced by the particular localization of AvrLml as a solo gene in the middle of an AT-rich isochore (Gout et al. 2006).
With AvrLm6 being localized in the same genomic context as AvrLml (Fudal et al. 2007), the availability of collections of isolates experimentally submitted to the Rlm6 selection pressure, followed by the setting up of novel experimental fields aiming to study the dynamics of Rlm6 breakdown (this study), provides us here with material of choice to analyze whether AvrLm6 would evolve to virulence through the same molecular mechanisms as AvrLml or by other mechanisms. Thus, we analyzed the occurrence of deletions and their extent, along with nucleotide polymorphism at the AvrLm6 locus, to identify the different molecular events leading to virulence under Rlm6 selection pressure. In particular, evaluation of allelic variability of AvrLm6 in avirulent and virulent isolates led us to identify RIP as a novel, still-undocumented mechanism of adaptation to resistance-gene selection pressure. The influence of the genomic context on the evolution of AvrLm6 is discussed.

\section{RESULTS}

Identification of isolates virulent toward Rlm6.

A large-scale survey of $L$. maculans races in France, genotyping 1,797 isolates from 20 different locations for nine $A V R$ loci (AvrLml to AvrLm9), highlighted a very low frequency of avrLm6 isolates (only one isolate virulent toward Rlm6) (Balesdent et al. 2006), consistent with the current absence of Rlm6 in commercial cultivars. This current scarcity of virulent isolates in field populations made it necessary that we analyze isolates obtained during experiments aiming to apply an Rlm6 selection pressure to field populations and to evaluate the speed of breakdown of Rlm6 resistance (Table 1). All but two

Table 1. List and characteristics of the isolates used in this study

\begin{tabular}{|c|c|c|c|c|c|c|c|c|c|}
\hline \multirow[b]{2}{*}{ Isolates $^{c}$} & \multirow[b]{2}{*}{ Short name } & \multirow[b]{2}{*}{ Year } & \multirow[b]{2}{*}{ Country } & \multicolumn{2}{|c|}{ Host plant ${ }^{\mathrm{a}}$} & \multirow[b]{2}{*}{$n$} & \multicolumn{2}{|c|}{ Phenotype $^{\text {b }}$} & \multirow[b]{2}{*}{ Provider (ref.) ${ }^{d}$} \\
\hline & & & & Species & Cultivar & & AvrLm6 & avrLm6 & \\
\hline \multicolumn{10}{|l|}{ Field } \\
\hline Versailles & V03x & 2003 & France & Brassica. napus & Westar & 4 & 4 & 0 & L. Gout (7) \\
\hline Oucques & Ox & 2000 & France & B. napus & Westar & 7 & 7 & 0 & M. H. Balesdent (6) \\
\hline Mondonville & $\mathrm{Bx}$ & 2000 & France & B. napus & Westar & 5 & 5 & 0 & M. H. Balesdent (6) \\
\hline Laxou & $\mathrm{Lx}$ & 2000 & France & B. napus & Westar & 3 & 3 & 0 & M. H. Balesdent (6) \\
\hline Toury & $\mathrm{Mx}$ & 2000 & France & B. napus & Westar & 9 & 8 & 1 & M. H. Balesdent (6) \\
\hline \multicolumn{10}{|l|}{ Experimental } \\
\hline Rennes & $\begin{array}{l}\text { EF03-x or } \\
\text { ExF03-x }\end{array}$ & 2003 & France & B. napus & Eurol, Eurol MX & 20 & 0 & 20 & H. Brun \\
\hline Rennes & $\mathrm{Rx}$ or $\mathrm{MXx}$ & 1992-93 & France & B. napus & MX line & 10 & 0 & 10 & H. Brun (1) \\
\hline Rennes & SamR-Fx & 1995 & France & B. napus & Samourai MX & 3 & 0 & 3 & H. Brun (2) \\
\hline Rennes & $\mathrm{R} 1 \mathrm{x}$ & 2001 & France & B. napus & $\begin{array}{l}\text { S MX, Maxol } \\
\text { MX, Falcon MX, } \\
\text { Eurol, Eurol MX }\end{array}$ & 25 & 1 & 24 & H. Brun \\
\hline $\begin{array}{l}\text { Saint Florent } \\
\text { Reference }\end{array}$ & $\mathrm{C} 1 \mathrm{x}$ or $\mathrm{C} 2 \mathrm{x}$ & $2000-01$ & France & B. napus & Eurol MX & 9 & 1 & 8 & H. Brun \\
\hline $\mathrm{v} 23.1 .3$ & $\ldots$ & - & In vitro cross & - & $\ldots$ & $\ldots$ & 1 & $\ldots$ & M. H. Balesdent (3) \\
\hline v29.3.1 & $\ldots$ & - & In vitro cross & - & $\ldots$ & $\ldots$ & $\ldots$ & 1 & M. H. Balesdent (4) \\
\hline BBA 62908 & $\ldots$ & 1966 & Germany & - & $\ldots$ & $\ldots$ & 1 & $\ldots$ & \\
\hline IBCN 16 & $\ldots$ & 1988 & Australia & B. napus & $\ldots$ & $\ldots$ & $\ldots$ & 1 & P. Salisbury (5) \\
\hline IBCN 18 & $\ldots$ & 1988 & Australia & B. napus & $\ldots$ & $\ldots$ & $\ldots$ & 1 & P. Salisbury (5) \\
\hline IBCN 42 & $\ldots$ & 1990 & France & B. napus & $\ldots$ & $\ldots$ & 1 & $\ldots$ & $\begin{array}{l}\text { C. Gall/M. H. } \\
\text { Balesdent (5) }\end{array}$ \\
\hline IBCN 44 & $\ldots$ & 1990 & France & B. napus & $\ldots$ & $\ldots$ & 1 & $\ldots$ & $\begin{array}{l}\text { C. Gall/M. H. } \\
\text { Balesdent (5) }\end{array}$ \\
\hline IBCN 73 & $\ldots$ & - & Germany & - & $\ldots$ & $\ldots$ & 1 & $\ldots$ & P. H. Williams (5) \\
\hline IBCN 74 & $\ldots$ & $1970 \mathrm{~s}$ & France & B. oleracea & $\ldots$ & $\ldots$ & 1 & $\ldots$ & L. Lacoste (5) \\
\hline UWA M3 & $\ldots$ & 2001 & Australia & B. napus & $\ldots$ & $\ldots$ & $\ldots$ & 1 & M. Barbetti \\
\hline Total & $\ldots$ & $\ldots$ & $\ldots$ & $\ldots$ & $\ldots$ & 105 & 35 & 70 & $\ldots$ \\
\hline
\end{tabular}

a $-=$ No data.

b Interaction phenotype with Rlm6 plants. AvrLm6: avirulent isolates. avrLm6: virulent isolates. The interaction phenotype (AvrLm6 or avrLm6) of L. maculans isolates was assessed following inoculation on a line harboring the Rlm6 resistance gene (Darmor-MX), as previously described (Balesdent et al. 2005).

${ }^{\mathrm{c}}$ Field populations, experimental isolates, and reference isolates.

${ }^{\mathrm{d}}$ References: 1, Somda et al. 1999; 2, Brun et al. 2000; 3, Balesdent et al. 2001; 4, Balesdent et al. 2002; 5, Mendes-Pereira et al. 2003; 6, Balesdent et al. 2006; 7, Gout et al. 2006 
of these latter isolates (97\%) were virulent on the Rlm6 line Darmor-MX (Table 1). In addition to the reference AvrLm6 and avrLm6 isolates resulting from in vitro crosses, a total number of 103 isolates was analyzed. Of these, 69 were virulent toward Rlm6 (Table 1).

\section{Definition of race-specific primers.}

Two sets of primers, termed AvrLm6extU/L and AvrLm6intU/L, were used in order to amplify AvrLm6: the external set of primers was specific to the promoter and the $3^{\prime}$ untranslated region (UTR) of AvrLm6 and the internal primer set was bound to the coding sequence of AvrLm6 (140 and 490 bp after the ATG) (Fig. 1). As expected, AvrLm6 was amplified by the two sets of primers in all the avirulent isolates. In contrast, AvrLm6 was only amplified in 24 of 68 virulent isolates when using the internal primers and in 5 virulent isolates when using the external primers (also amplified by the internal primers) (Table 2). Thus, the external AvrLm6 primers seem to preferentially amplify avirulent isolates with an overall diagnosis efficiency of $92.86 \%$ (Tables 2 and 3 ).

\section{Polymorphism of AvrLm6 in avirulent isolates.}

AvrLm6 avirulent alleles were amplified by polymerase chain reaction (PCR) using the external AvrLm6 primers and sequenced in the 35 avirulent isolates (Table 1). The sequences obtained were compared with the AvrLm6 sequence of the reference isolate v23.1.3 in which AvrLm6 was first cloned (Fudal et al. 2007). A very limited nucleotide polymorphism was observed (eight polymorphic sites) and only six isolates exhibited polymorphism compared with v23.1.3. These isolates corresponded to the oldest isolates of our samples (IBCN 74 and BBA62908) and to some recent French isolates (C2E6-1 with three polymorphisms in the 5' UTR; V03-M4-305, B03-12, and B04-01 with one common polymorphic site). Of the eight polymorphic sites identified, five were located in the coding sequence: one polymorphism was shared by five isolates, while the four others were found in only one isolate each. The five polymorphisms located in the coding sequence all corresponded to $\mathrm{C}>\mathrm{T}$ or $\mathrm{G}>\mathrm{A}$ transitions (Table 4 ). These polymorphisms resulted in nonsynonymous mutations at the protein level ( $\mathrm{V}^{2}$ to $\mathrm{M}^{2}$ in IBCN74, BBA62908, V03-M4-305, B03-12, and $\mathrm{B} 04-01 ; \mathrm{F}^{68}$ to $\mathrm{L}^{68}$ and $\mathrm{K}^{156}$ to $\mathrm{E}^{156}$ in IBCN 74; and $\mathrm{S}^{70}$ to $\mathrm{G}^{70}$ in BBA62908) (Fig. 2).

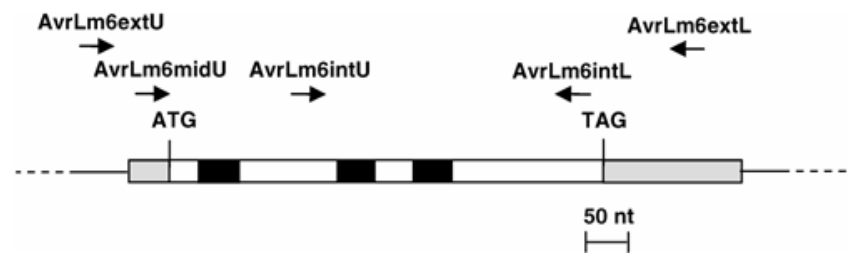

Fig. 1. Organization of the AvrLm6 gene and locations of the primers used in this study. The $5^{\prime}$ and $3^{\prime}$ untranslated regions are indicated by gray boxes. Exons are indicated by open boxes. Introns are indicated by black boxes. Locations of the primers used in this study are indicated as arrows.
Evaluation of the presence of AvrLm6 in virulent isolates.

AvrLm6 was amplified in only $34 \%$ of the virulent isolates when using the internal primers. In order to determine whether the absence of amplification corresponded to an absence of the gene in the corresponding isolates, the presence of AvrLm6 was analyzed by Southern blot analysis in a subset of isolates. Chromosomal DNA of 18 virulent isolates was digested by SalI, separated by CHEF (contour-clamped homogeneous electric fields) electrophoresis, and hybridized with an AvrLm6 probe. The blots were also hybridized with an $L m C y s 1$ probe, corresponding to a single-copy gene present on the same SalI fragment as AvrLm6 in v23.1.3 (Fudal et al. 2007), in order to determine the size of the SalI fragment in the virulent isolates lacking AvrLm6. The SalI restriction fragment encompassing AvrLm6 was $215 \mathrm{~kb}$ in v23.1.3, which is in accordance with the sequence data (Table 3). The AvrLm6 probe gave a hybridization signal for 7 of 18 virulent isolates. These all corresponded to the isolates amplified using the internal AvrLm6 primers and one isolate for which both external and internal primers allowed amplification of the gene (Table 3). The AvrLm6 gene, or at least the part of the gene amplified by the internal primers, is thus extrapolated to be present in $34.78 \%$ of the virulent isolates (Table 2).

When using LmCys1 as a probe, the size of the SalI fragment containing AvrLm6 was shown to be variable, 145 to 314 $\mathrm{kb}$ (Table 3). Half of the virulent isolates, however, shared the same fragment size $(215 \mathrm{~kb})$ as that of the AvrLm6 reference isolate. Interestingly, in nine virulent isolates, the SalI fragment was bigger ( 224 to $314 \mathrm{~kb}$ ) than that of the AvrLm6 reference isolate (Table 3). In virulent isolates lacking AvrLm6, the SalI fragment was very variable in size. No correlation could be found between the absence of the gene and the size of the SalI fragment, giving no evidence for a unique event of deletion and, thus, contrasting with the AvrLm1 deletion case (Gout et al. 2007).

\section{Organization of the AvrLm6 genomic region in the virulent isolate v29.3.1.}

Based on the known sequence of a bacterial artificial chromosome (BAC) contig spanning AvrLm6 in the avirulent isolate v23.1.3 (Fudal et al. 2007), we identified the corresponding BAC clone contig for the virulent isolate v29.3.1. The 5' part of the region has already been described and BAC clones V29-38D1 and V29-41F7 were previously sequenced (Gout et al. 2007) (Fig. 3). The v29.3.1 BAC library was screened by PCR using BAC pools as described by Gout and associates (2006, 2007) and BAC clones V29-55E6 and V29-51C1 were identified by using markers generated from the sequence of the single-copy genes $L m C y s 1$ and $L m M F S$, respectively (Fudal et al. 2007) (Fig. 3). The marker 55E6F was designed after BAC end sequencing of 55E6 and a new BAC clone, V29-35C8, was identified. The three BAC clones V29-55E6, V29-51C1, and V29-35C8 were sequenced by Genoscope. The final contig had a size of 235,218 bp and included two gaps (Fig. 3). Sequence analysis confirmed the absence of sequences homologous to AvrLm6 in the AvrLm6/v29.3.1 contig. Analysis of the GC content, gene density, and repeat distribution in the

Table 2. Estimation of AvrLm6 presence in avirulent and virulent isolates using a polymerase chain reaction (PCR) test

\begin{tabular}{lccc}
\hline & & & Percent PCR amplification (number) $^{\mathbf{a}}$ \\
\cline { 3 - 4 } Phenotype $^{\mathbf{b}}$ & No. of isolates tested & $\boldsymbol{\beta}$-TubulinU/L & AvrLm6extU/L \\
\hline AvrLm6 & 35 & $100(35)$ & $100(35)$ \\
avrLm6 & 70 & $100(70)$ & $7.14(5)$ \\
\hline
\end{tabular}

${ }^{a}$ Percentage and number of isolates amplified by PCR using external (AvrLm6extU/L) and internal AvrLm6 primers (AvrLm6intU/L), and primers specific to $\beta$-tubulin as a control $(\beta$-tubulinU/L).

${ }^{\mathrm{b}}$ Interaction phenotype toward Rlm6 plants. AvrLm6: avirulent isolates and avrLm6: virulent isolates. 
AvrLm6/v29.3.1 revealed the same organization as in the v23.1.3 contig (Fig. 3), which was already characterized to have highly conserved GC-equilibrated regions, gene-rich regions (Fudal et al. 2007), and large AT-rich regions comprising RIP-degenerated, truncated copies of the four long terminal repeat (LTR) retrotransposons Pholy, Olly, Rolly, and Polly (Gout et al. 2006) (Figs. 3 and 4). Although GC-equilibrated regions were highly conserved, large structural reorganizations were observed in AT-rich regions between AvrLm6/v23.1.3 and v29.3.1 contigs (Fig. 4). In contrast to what was observed for the AvrLm1 region of the same isolates (Gout et al. 2007), the AT-rich region of the AvrLm6 contig showed numerous divergent mosaics, of which some are likely to be due to events of insertion of retrotransposons or to deletions (only maintaining solo LTR). Three highly polymorphic regions were identified, one corresponding to the AvrLm6 locus (Fig, 4). The presence of several sources of variations in the region explains why the size variations of the SalI fragment containing AvrLm6 was not related to the absence of AvrLm6 (Fig. 4).

\section{Polymorphism of AvrLm6 in virulent isolates.}

The AvrLm6-virulent alleles were sequenced using the fragment generated by the internal primers (AvrLm6intU/L) for all
24 isolates in which the gene (or part of it) was present. Of these, additional sequencing was performed on the external fragment (AvrLm6extU/L) for the 5 isolates amplifying it and on an intermediate-sized fragment (AvrLm6midU/AvrLm6intL) for 15 of the remaining isolates (Fig. 1; Tables 2 and 3). Four of the five alleles amplified by the external primers only displayed a few point mutations compared with the reference avirulent allele of v23.1.3. R1Max5-4, R1Max1-2, and R1Max1-3 (which were collected the same year in the same field and on the same plant for two of them) shared the same point mutation at the nucleotide level, which resulted in the generation of a premature stop codon at the protein level, leading to a dramatically truncated protein (Fig. 2). EF03-24-1 exhibited three mutations compared with v23.1.3, only one mutation being nonsilent at the protein level with a tyrosine (aromatic) to a histidine (basic) change. In all the other isolates, the nucleotide diversity was high compared with v23.1.3 (4 to $9 \%$, corresponding to 83 polymorphic sites in which 64 were found in the coding sequence) (Tables 4 and 5), thus explaining some difficulties experienced in amplifying the virulent alleles. Forty (29.17\%) polymorphic sites were identified over the 144 amino acids of AvrLm6 and resulted in the generation of 2 to 4 stop codons in each sequence. Splicing sites of the introns were also mutated, which probably alters the

Table 3. Presence of AvrLm6 in a sample of virulent isolates using Southern blot analysis and correlation between polymerase chain reaction (PCR) amplification of AvrLm6 virulent alleles and nucleotide polymorphism

\begin{tabular}{|c|c|c|c|c|c|c|c|c|c|}
\hline \multirow[b]{2}{*}{ Isolate } & \multirow[b]{2}{*}{ Location $^{\mathrm{c}}$} & \multirow[b]{2}{*}{ Year } & \multirow[b]{2}{*}{ Avr ${ }^{d}$} & \multicolumn{2}{|c|}{ Southern analysis ${ }^{\mathrm{a}}$} & \multicolumn{3}{|c|}{ PCR amplification ${ }^{b}$} & \multirow[b]{2}{*}{ Sequence compared with v23.1.3 } \\
\hline & & & & Hybrid & SalI (kb) & $\beta$-Tub & Ext & Int & \\
\hline $\mathrm{v} 23.1 .3$ & In vitro cross & $\ldots$ & A6 & + & 215 & + & + & + & $\ldots$ \\
\hline $\mathrm{v} 29.3 .1$ & In vitro cross & $\ldots$ & a6 & - & 270 & + & - & - & $\ldots$ \\
\hline IBCN18 & Australia & 1988 & a6 & - & 215 & + & - & - & $\ldots$ \\
\hline M3-10 & Toury & 2000 & a6 & - & 145 & + & - & - & $\ldots$ \\
\hline UWA M3 & Australia & 2001 & a6 & - & 215 & + & - & - & $\ldots$ \\
\hline R4 & Rennes & 1992 & a6 & - & 215 & + & - & - & $\ldots$ \\
\hline $\mathrm{R} 8$ & Rennes & 1992 & a6 & - & 215 & + & - & - & $\ldots$ \\
\hline $\mathrm{R} 13$ & Rennes & 1992 & a6 & - & 215 & + & - & - & $\ldots$ \\
\hline MX7-19 & Rennes & 1993 & a6 & - & 215 & + & - & - & $\ldots$ \\
\hline MX8-12 & Rennes & 1993 & a6 & + & 224 & + & - & + & Many point mutations \\
\hline MX8-14 & Rennes & 1993 & a6 & + & 314 & + & - & + & Many point mutations \\
\hline SamR F1M1 & Rennes & 1995 & a6 & + & 224 & + & - & + & Many point mutations \\
\hline Sam R F3M2 & Rennes & 1995 & a6 & - & 215 & + & - & - & $\ldots$ \\
\hline SamR F9M1 & Rennes & 1995 & a6 & - & 215 & + & - & - & $\ldots$ \\
\hline ExF03-3-2 & Rennes & 2003 & a6 & + & 259 & + & - & + & Many point mutations \\
\hline ExF03-5-2 & Rennes & 2003 & a6 & + & 314 & + & - & + & Many point mutations \\
\hline ExF03-29-1 & Rennes & 2003 & a6 & - & 259 & + & - & - & $\ldots$ \\
\hline EF03-3-2 & Rennes & 2003 & a6 & - & 259 & + & - & - & $\ldots$ \\
\hline EF03-14-2 & Rennes & 2003 & a6 & + & 259 & + & - & + & Three point mutations \\
\hline EF03-24-1 & Rennes & 2003 & $\mathrm{a} 6$ & + & 215 & + & + & + & Single point mutation \\
\hline R1Max 1-2 & Rennes & 2001 & a6 & nd & nd & + & + & + & Single point mutation \\
\hline R1Max 1-3 & Rennes & 2001 & a6 & nd & nd & + & + & + & Single point mutation \\
\hline R1Max5-4 & Rennes & 2001 & a6 & nd & nd & + & + & + & Single point mutation \\
\hline ExF03-7-2 & Rennes & 2003 & a6 & nd & nd & + & - & + & Many point mutations \\
\hline ExF03-15-3 & Rennes & 2003 & $\mathrm{a} 6$ & nd & nd & + & - & + & Many point mutations \\
\hline ExF03-32-3 & Rennes & 2003 & a6 & nd & nd & + & - & + & Many point mutations \\
\hline ExF03-33-1 & Rennes & 2003 & a6 & nd & nd & + & - & + & Many point mutations \\
\hline ExF03-37-3 & Rennes & 2003 & a6 & nd & nd & + & - & + & Many point mutations \\
\hline ExF03-40-3 & Rennes & 2003 & a6 & nd & nd & + & - & + & Many point mutations \\
\hline ExF03-41-1 & Rennes & 2003 & a6 & nd & nd & + & - & + & Many point mutations \\
\hline EF03-22-3 & Rennes & 2003 & a6 & nd & nd & + & - & + & Many point mutations \\
\hline EF03-31-3 & Rennes & 2003 & a6 & nd & nd & + & - & + & Many point mutations \\
\hline C1E7-5 & St. Florent & 2000 & a6 & nd & nd & + & - & + & Many point mutations \\
\hline R1F10-2 & Rennes & 2001 & a6 & nd & nd & + & - & + & Many point mutations \\
\hline $\mathrm{R} 1 \mathrm{~F} 11-8$ & Rennes & 2001 & a6 & nd & nd & + & - & + & Many point mutations \\
\hline R1F13-1 & Rennes & 2001 & a6 & nd & nd & + & + & + & Many point mutations \\
\hline R1E4-2 & Rennes & 2001 & a6 & nd & nd & + & - & + & Many point mutations \\
\hline
\end{tabular}


splicing of intron 1 for five isolates and intron 3 for 12 isolates (Fig. 2).

The percentage of mutations in the coding and noncoding regions of the gene varied between 4 and $20 \%$, with the higher percentage of mutations being found in exons 2 and 3 (Table 5). However, this result has to be considered cautiously because the number of sequences was variable, depending on the gene region: 25 sequences were obtained for exons 2,3 , and 4 and introns 2 and 3, but only 4 to 13 sequences were obtained for the promoter, exon 1, and intron 1, and part of exons 2 and 4. In spite of the different number of sequences available, no main differences in the mutation intensity could be observed between the coding and noncoding regions. The GC content in the corresponding virulent alleles was decreased from 43.6 to $33 \%$, and the ratio of $\mathrm{G}>\mathrm{A}$ and $\mathrm{C}>\mathrm{T}$ mutations represented almost $100 \%$ of the mutations. The avrLm6 alleles also showed a bias in the occurrence of dinucleotides, with an underrepresentation of the $\mathrm{CpA}$ and $\mathrm{TpG}$ dinucleotides and a strong overrepresentation of the TpA dinucleotide (Table 4). The $\mathrm{TpA} / \mathrm{ApT}$ and $\mathrm{CpA}+\mathrm{TpG} / \mathrm{ApC}+\mathrm{GpT}$ indices showed great differences between the AvrLm6 allele of v23.1.3 and the 19 avrLm6 alleles of the virulent isolates, indicating the presence of many point mutations (Table 4). All these data are indicative of sequences having undergone RIP (Attard et al. 2005; Galagan et al. 2003).

A great diversity of mutation patterns was observed, with 17 virulent alleles identified among the 24 isolates in which AvrLm6 was sequenced. Except for some of the isolates that shared a common pattern of mutations (R1Max5-4, R1Max1-2 and R1Max1-3; ExF03-7-2 and ExF03-91-1; and ExF03-15-3, ExF03-33-1, ExF03-37-3, ExF03-5-2, and ExF03-30-3) (Fig. 2 ), a diversity of mutation patterns was even found for isolates that were collected the same year in the same field.

\section{DISCUSSION}

Similarly to AvrLm1, AvrLm6 is located in a large genomic region devoid of active coding sequences and consisting of mosaics of truncated and degenerated retrotransposons (Fudal et al. 2007; Gout et al. 2006). In the case of AvrLm1, this had three main consequences: i) a strong suppression of meiotic recombination (Gout et al. 2006), as also observed for AvrLm6 (Fudal et al. 2007); ii) a very low level of nucleotide polymorphism in the avirulent alleles of the gene (Gout et al. 2007); and iii) a large-size deletion event being the favored event leading to virulence (Gout et al. 2007). Here, we investigate the last two traits on the second "lost in the middle of nowhere" AVR gene of L. maculans, AvrLm6.

AvrLm1 avirulent alleles were extremely monomorphic: three polymorphic sites, of which only two were located in the coding region of the gene, and only one leading to a nonsynonymous mutation, were identified in 11 of 41 isolates (Gout et al. 2007). Even though the samples analyzed are not comparable with those analyzed by Gout and associates (2007), the analysis of AvrLm6 alleles showed two specific features compared with those of AvrLm1: nucleotide polymorphism at the AvrLm6 locus is found in fewer isolates than for AvrLml (17 versus 27\% for AvrLm1) (Gout et al. 2007) but more polymorphic sites are ob-

Table 4. Bases composition, structural features, number and type of mutations, and RIP indices of AvrLm6 avirulent and virulent alleles ${ }^{\mathrm{a}}$

\begin{tabular}{|c|c|c|c|c|c|c|c|c|c|c|c|}
\hline Isolate & $\begin{array}{l}\text { Size } \\
\text { (bp) }\end{array}$ & $\begin{array}{c}\mathbf{G}+\mathbf{C} \\
\text { content } \\
(\%)\end{array}$ & $\begin{array}{l}\text { Identities with } \\
\text { v23.1.3 allele of } \\
\text { AvrLm6 }(\%)\end{array}$ & $\begin{array}{l}\text { No. of } \\
\text { stop } \\
\text { codons }\end{array}$ & $\begin{array}{c}\text { No. of } \\
\text { mutations } \\
(\%)^{b}\end{array}$ & $\begin{array}{c}\text { Ratio of } G \text { to } \\
\text { A or C to T } \\
\text { mutations }\end{array}$ & $\begin{array}{c}\text { CpA } \\
\text { occurrence } \\
\text { O/E }\end{array}$ & $\begin{array}{c}\text { TpA } \\
\text { occurrence } \\
\text { O/E }\end{array}$ & $\begin{array}{c}\text { TpG } \\
\text { occurrence } \\
\text { O/E }\end{array}$ & $\mathbf{T p A} / \mathbf{A p} \mathbf{T}^{\mathrm{c}}$ & $\begin{array}{c}\text { CpA + } \\
\text { TpG/ApC + } \\
\text { GpT }\end{array}$ \\
\hline v23.1.3 & 773 & 43.6 & & 1 & & $\cdots$ & $\ldots$ & $\ldots$ & & 1.12 & 1.02 \\
\hline BBA 62908 & 773 & 43.7 & 99.5 & 1 & $4(0.5)$ & 25 & 0.98 & 1 & 1 & 1.11 & 1.02 \\
\hline IBCN74 & 773 & 44 & 99.7 & 1 & $2(0.3)$ & 50 & 1.02 & 0.98 & 1 & 1.09 & 1.04 \\
\hline V03-M4-305 & 671 & 44.1 & 99.8 & 1 & $1(0.2)$ & 100 & 1 & 1 & 1 & 1.17 & 0.99 \\
\hline B03-12 & 652 & 44.2 & 99.8 & 1 & $1(0.2)$ & 100 & 1 & 1 & 1 & 1.15 & 0.99 \\
\hline B04-01 & 652 & 44.2 & 99.8 & 1 & $1(0.2)$ & 100 & 1 & 1 & 1 & 1.15 & 0.99 \\
\hline C2E6-1 & 524 & 43.7 & 99.6 & 1 & $3(0.4)$ & 0 & 1 & 1 & 1 & 1.29 & 0.89 \\
\hline R1Max 1-2 & 524 & 43.5 & 99.8 & 2 & $1(0.2)$ & 0 & 0.94 & 0.96 & 1 & 1.29 & 0.89 \\
\hline R1Max 1-3 & 527 & 43.3 & 99.8 & 2 & $1(0.2)$ & 0 & 0.94 & 0.96 & 1 & 1.31 & 0.89 \\
\hline R1Max 5-4 & 623 & 44.8 & 99.8 & 2 & $1(0.2)$ & 0 & 1 & 1 & 1 & 1.22 & 0.97 \\
\hline EF03-24-1 & 773 & 44 & 99.6 & 1 & $3(0.4)$ & 0 & 1.04 & 0.97 & 1 & 1.11 & 1.02 \\
\hline R1F13-1 & 583 & 42 & 96.9 & 4 & $18(3.1)$ & 100 & 0.85 & 1.23 & 0.9 & 1.48 & 0.84 \\
\hline EF03-14-2 & 339 & 37.9 & 95 & 3 & $17(5)$ & 100 & 0.9 & 1.38 & 0.95 & 1.24 & 1.03 \\
\hline ExF03-7-2 & 327 & 37.2 & 95 & 3 & $16(5)$ & 100 & 0.75 & 1.44 & 0.81 & 1.62 & 0.80 \\
\hline ExF03-91-1 & 327 & 37.2 & 95 & 3 & $16(5)$ & 100 & 0.8 & 1.44 & 0.75 & 1.62 & 0.82 \\
\hline C1E7-5 & 529 & 38.4 & 94.6 & 2 & $28(5.4)$ & 100 & 0.9 & 1.31 & 0.81 & 1.58 & 0.83 \\
\hline R1E4-2 & 386 & 37.3 & 94 & 3 & $23(6)$ & 100 & 1 & 1.37 & 0.7 & 1.92 & 0.69 \\
\hline ExF03-3-2 & 533 & 37.1 & 93 & 3 & $36(7)$ & 94.4 & 0.97 & 1.4 & 0.62 & 1.68 & 0.80 \\
\hline SamRF1M1 & 608 & 35 & 92.6 & 4 & $39(6.4)$ & 100 & 0.92 & 1.47 & 0.63 & 1.53 & 0.82 \\
\hline MX8-12 & 517 & 37.3 & 92.4 & 4 & 34 (6.6) & 97.1 & 1 & 1.43 & 0.65 & 1.74 & 0.76 \\
\hline MX8-14 & 608 & 35.9 & 92.4 & 3 & $40(6.6)$ & 90 & 0.82 & 1.45 & 0.67 & 1.6 & 0.86 \\
\hline R1F10-2 & 524 & 37 & 92.2 & 3 & $35(6.8)$ & 100 & 0.9 & 1.43 & 0.65 & 1.72 & 0.74 \\
\hline R1F11-8 & 469 & 35.8 & 92.1 & 3 & 37 (7.9) & 100 & 1 & 1.62 & 0.54 & 1.91 & 0.71 \\
\hline EF03-22-3 & 348 & 34.1 & 91 & 4 & $30(9)$ & 100 & 0.85 & 1.71 & 0.63 & 1.66 & 0.91 \\
\hline EF03-31-3 & 324 & 33.5 & 91 & 4 & $28(9)$ & 100 & 0.8 & 1.73 & 0.62 & 1.61 & 0.87 \\
\hline ExF03-15-3 & 349 & 34.6 & 91 & 4 & $29(9)$ & 100 & 0.85 & 1.68 & 0.68 & 1.62 & 0.86 \\
\hline ExF03-32-3 & 326 & 33.6 & 91 & 3 & $27(9)$ & 100 & 0.85 & 1.67 & 0.625 & 1.61 & 0.90 \\
\hline ExF03-33-1 & 326 & 33 & 91 & 4 & $29(9)$ & 100 & 0.8 & 1.74 & 0.56 & 1.68 & 0.83 \\
\hline ExF03-37-3 & 326 & 33 & 91 & 4 & $29(9)$ & 100 & 0.8 & 1.74 & 0.56 & 1.68 & 0.83 \\
\hline ExF03-5-2 & 326 & 33 & 91 & 4 & $29(9)$ & 100 & 0.8 & 1.74 & 0.56 & 1.68 & 0.83 \\
\hline ExF03-90-3 & 326 & 33 & 91 & 4 & $29(9)$ & 100 & 0.8 & 1.74 & 0.56 & 1.68 & 0.83 \\
\hline
\end{tabular}

${ }^{a}$ Dinucleotide frequencies are expressed as the observed occurrence over the expected number $(\mathrm{O} / \mathrm{E})$.

${ }^{\mathrm{b}}$ Number and percentage of mutations compared with v23.1.3.

${ }^{\mathrm{c}}$ According to Galagan and associates (2003), TpA/ApT $>2.0$ or $\mathrm{CpA}+\mathrm{TpG} / \mathrm{ApC}+\mathrm{GpT}<0.7$ corresponds to regions predicted as repeat-induced pointmutated in Neurospora crassa. BBA, IBCN74, V03-M4-305, B03-12, and B04-01 are avirulent toward Rlm6 while all the other isolates are virulent. BBA, IBCN74, M4305, B03-12, and B04-01 are the only avirulent isolates that showed polymorphism at AvrLm6 locus compared with v23.1.3. 
served in AvrLm6 compared with AvrLm1, with eight polymorphic sites at the nucleotide level leading to four nonsynonymous mutations at the protein level, suggesting that AvrLm6 could be submitted to a limited positive diversifying selection, leading to an accumulation of nonsynonymous point mutations allowing diversification of AVR proteins as observed in other plant pathogens such as Melampsora lini (Ellis et al. 2007) or Hyaloperonospora parasitica (Rehmany et al. 2005). More interestingly, five of these mutations are indicative of RIP. One of the common traits (and main characteristics compared with other fungal $A V R$ genes) of the three $A V R$ genes currently cloned in $L$. maculans is their much lower GC content compared with other coding sequences and available expressed sequence tag sequences of the genome (Parlange et al. 2009). In accordance with this low GC content, the existence of mutations due to RIP in functional AvrLm6 alleles thus questions whether RIP is acting in this species as a positive diversification process as well as an inactivation process (see below) eventually leading to novel AVR-effector specificities.

The major event leading to virulence toward Rlml is the deletion of the gene which was observed in $98.3 \%$ of the virulent isolates and which, in $90 \%$ of the cases, corresponded to the deletion of a $260-\mathrm{kb}$ repeat-rich chromosomal fragment comprising the unique gene AvrLml but also to the insertion of a new genomic segment suggesting retrotransposon-mediated recombination (Gout et al. 2007). Compared with the evolution of AvrLm1, AvrLm6 is shown here to be submitted to more diversified mechanisms toward gene inactivation: deletion, one to three point mutations (not attributable to RIP), and RIP inactivation. Even if AvrLm6 was found to be present in much more virulent isolates than in the case of AvrLml (35 instead of $1.7 \%$ ) (Gout et al. 2007), the main event leading to virulence at the AvrLm6 locus is the deletion of the gene. As in the case of AvrLml, the deletion is accompanied by important modifications in the retrotransposon mosaics, with three polymorphic regions identified as potential sources of size variations. However, the deletions occurring at the AvrLm6 locus do not reveal any correlation between the absence of AvrLm6 and the size of the corresponding AT-rich region. Thus, they are much smaller than in the case of AvrLml and suggest that multiple events of deletion or insertion occurred at this locus. As in the case of AvrLml, the data provided here suggest that retrotransposons are key drivers in genome evolution and adaptation to novel selection pressure in L. maculans.
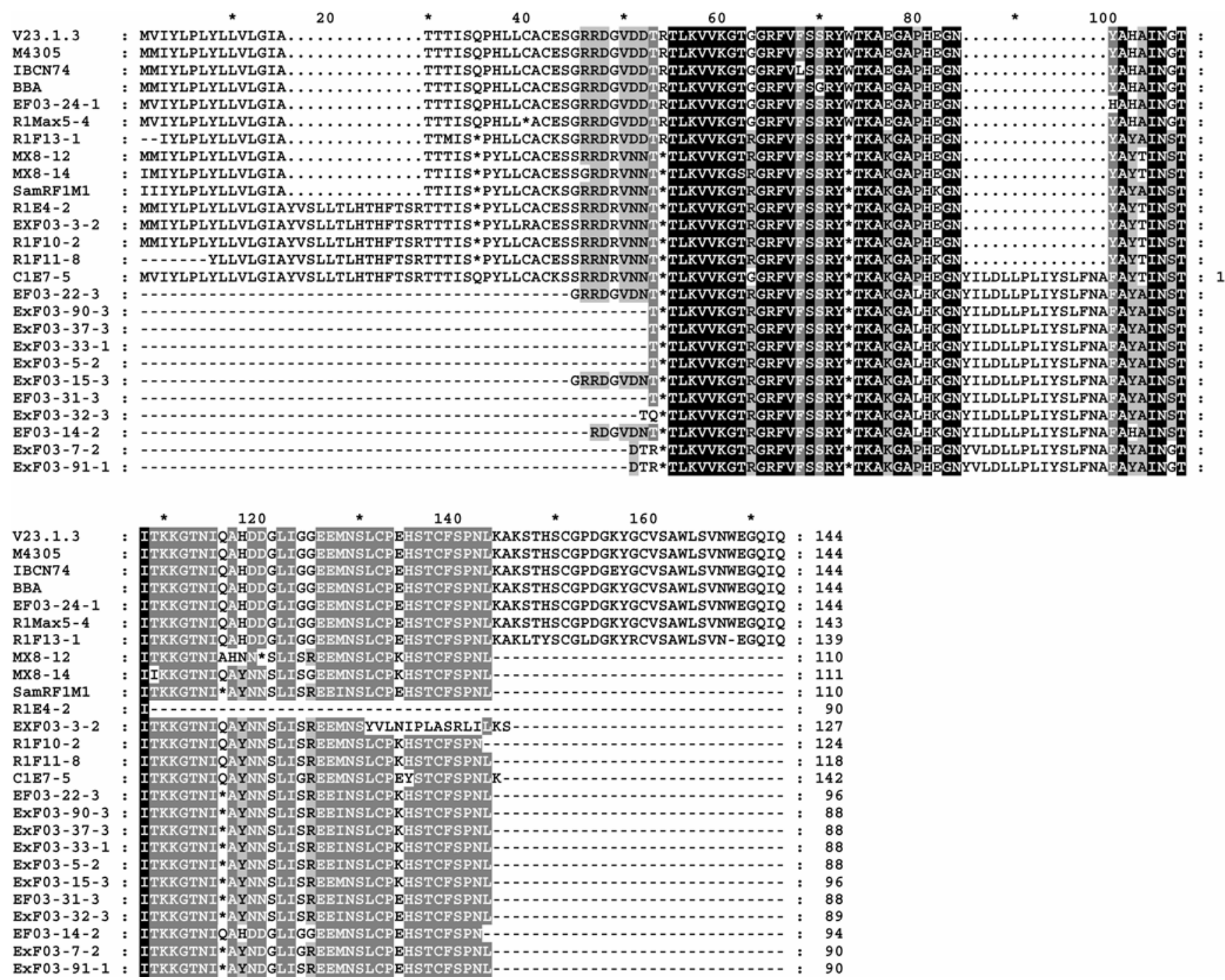

Fig. 2. GeneDoc-edited alignment of AvrLm6 protein sequence of three avirulent and 22 virulent isolates compared with the sequence in the reference avirulent isolate v23.1.3. BBA, IBCN74, and V03-M4-305 are avirulent toward Rlm6 while all the other isolates are virulent. B03-12 and B04-01 share the same sequence as V03-M4-305 and are not represented here. BBA, IBCN74, V03-M4-305, B03-12, and B04-01 are the only avirulent isolates that showed polymorphism at AvrLm6 locus compared with v23.1.3. The virulent isolates R1Max1-2 and R1Max1-3 share the same sequence as R1Max5-4 and are not represented in the alignment. Stop codons are indicated as stars. Points represent the absence of sequence (e.g., region with a spliced intron). Dashes indicate data not available. 
RIP, as defined in the model species Neurospora crassa, is a mechanism, specifically reported in fungi, which occurs during the sexual phase between fertilization and meiosis and which targets duplicated sequences whenever they are more than $400 \mathrm{bp}$ in size and share at least $80 \%$ of sequence identity (Watters et al. 1999). RIP consists of C:G to T:A transitions, with a significant preference for the $\mathrm{CpA}$ and $\mathrm{TpG}$ contexts (Attard et al. 2005; Cambareri et al. 1989; Idnurm and Howlett 2003), resulting in an irreversible gene alteration or even inactivation. In $N$. crassa, in a single passage through the sexual cycle, up to $30 \%$ of the $\mathrm{C}$ and $\mathrm{G}$ nucleotides in duplicated sequences can be mutated (Cambareri et al. 1989). The RIP mechanism was originally described in $N$. crassa (Cambareri et al. 1989) but, since then, also observed to operate on Podospora anserina (Graia et al. 2001) and L. maculans (Idnurm and Howlett 2003). L. maculans is a haploid fungus in which sexual mating is the primary mode of reproduction (Rouxel and Balesdent 2005), and the current active RIP mechanism is con-

\section{AvrLm6/v23.1.3 contig}

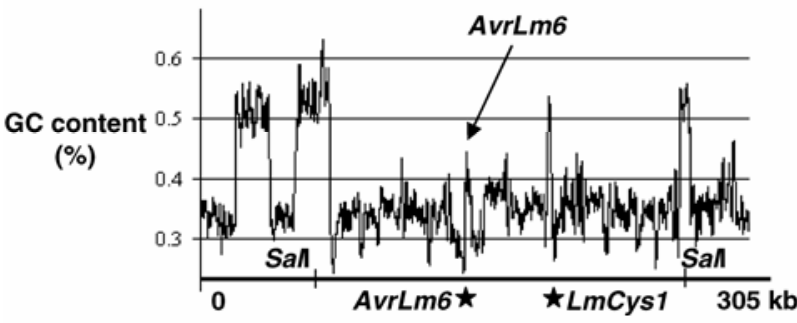

AvrLm6 / v29.3.1 contig

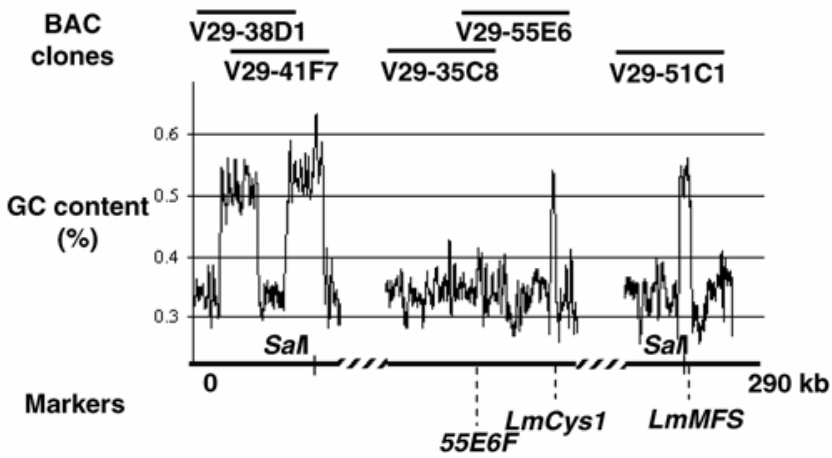

Fig. 3. Organization of the AvrLm6 genomic region in an avirulent (v23.1.3) and a virulent (v29.3.1) Leptosphaeria maculans isolate. GC content: analysis of the GC content in the two contigs (sliding window: size 1,000 bp, step $100 \mathrm{bp}$ ). Dashed lines indicate sequence gaps in the v29.3.1 contig sequence. Markers used for the chromosome walk and contig assembly are shown. The stars represent the probes used for Southern analysis. sistent with the key importance of sexual reproduction in its life cycle. In contrast, for fungi such as Magnaporthe grisea (Ikeda et al. 2002) and Aspergillus oryzae (Montiel et al. 2006), having lost the ability to cross in nature, RIP is not active and only signatures of RIP can be found. RIP is particularly extensive in $L$. maculans, as exemplified by the degeneration of the different copies of the retrotransposons located in the AvrLm1-AvrLm6 genomic region and by the low GC content of the corresponding retrotransposon-rich isochores. In the case of AvrLm1, only five virulent isolates (1.7\%) showed the presence of an AvrLml fragment, of which only two could be sequenced and showed an extensive mutation pattern that was hypothesized by the authors to be due to RIP (Gout et al. 2007). In the case of AvrLm6, many more virulent isolates (i.e., 35\%) carried a potentially incomplete copy of AvrLm6. In all except four isolates, this copy was highly mutated compared with the avirulent allele of v23.1.3, and a great variety of mutational patterns was observed. The GC content of these AvrLm6 alleles decreased from 44 to $33 \%$, and they showed all typical traits of sequences having undergone RIP mutations (overrepresentation of the TpA dinucleotides, mutations exclusively corresponding to $\mathrm{C}$ to $\mathrm{T}$ or $\mathrm{G}$ to $\mathrm{A}$ transitions, and so on). All these data are clearly indicative of a RIPlike effect acting on AvrLm6 to inactivate the gene, as was the case for very rare virulent alleles of AvrLm1. The occurrence of extensive RIP degeneration at the AvrLm6 locus, along with the retrospective reevaluation of effective occurrence of RIP mutations at the AvrLml locus, question i) a possible duplication of AvrLm6 and AvrLml in the ancestor of the corresponding virulent isolates, because RIP is supposed to act exclusively on duplicated sequences (Galagan and Selker 2004), or ii) a loose control of the RIP process in L. maculans that can have effect on a single-copy sequence lost in the middle of repetitive elements.

Table 5. Distribution of point mutations in the different coding and noncoding regions of AvrLm6 in virulent isolates compared with the reference avirulent isolate v23.1.3

\begin{tabular}{lccc}
\hline Region & $\begin{array}{c}\text { Size } \\
\text { (bp) }\end{array}$ & $\begin{array}{c}\text { No. of polymorphic } \\
\text { sites (\%) }\end{array}$ & $\begin{array}{c}\text { No. of sequences } \\
\text { available }^{\mathbf{a}}\end{array}$ \\
\hline Promoter + 5' UTR & 118 & $8(6.78)$ & 11 \\
exon 1 & 44 & $3(6.82)$ & 13 \\
intron 1 & 51 & $4(7.84)$ & 13 \\
exon 2 & 119 & $23(19.33)$ & $13 / 24$ \\
intron 2 & 47 & $2(4.26)$ & 24 \\
exon 3 & 50 & $10(20.00)$ & 24 \\
intron 3 & 48 & $5(10.42)$ & 24 \\
exon 4 & 222 & $28(12.61)$ & $24 / 4$ \\
\hline
\end{tabular}

${ }^{a}$ AvrLm6 virulent alleles were amplified by external primers (located in the promoter and $3^{\prime}$ untranslated region [UTR] of the gene) in 4 isolates, by internal primers (located in the exon 2 and exon 4 of the gene) in 24 isolates, and by intermediate primers (located in the 5' UTR and exon 4 of the gene) in 13 isolates.

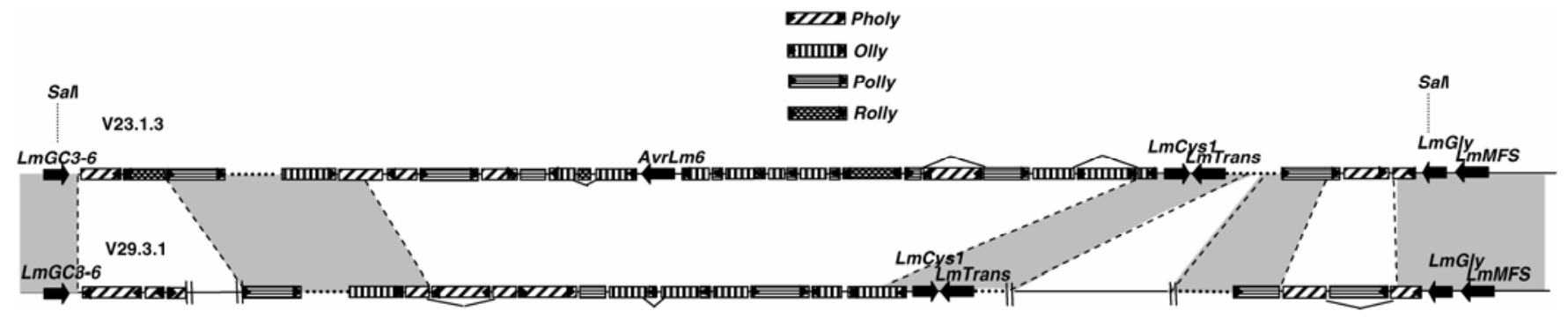

Fig. 4. Schematic organization of the AvrLm6 genomic region in v23.1.3 and v29.3.1. The plain black arrows indicate predicted genes, including AvrLm6. Boxes represent different long terminal repeat (LTR) retrotransposons flanked or not by LTR represented by small internal triangles. Small boxes with an internal triangle represent solo LTR. Absence of LTR at the 5' or $3^{\prime}$ ends of the retrotransposon indicates a truncated retrotransposon. Lines connecting two boxes indicate the presence of a unique retrotransposon interrupted by the insertion of another element. Gray areas connecting the two contigs represent regions with the same organization. Within these homologous regions, doted lines represent the same alternation of retrotransposons, not represented here. Dashed lines indicate sequence gaps in the v29.3.1 sequence. 
No second copy of AvrLm6 and AvrLml and no closely related paralog are present in the genome of the reference avirulent isolate v23.1.3 following a whole genome search (I. Fudal and J. Grandaubert, unpublished data), and no duplication of these genes was detected by CHEF hybridization or by subcloning and sequencing after PCR amplification in virulent isolates. Finally, no mixed electrophoregram, indicative of the presence of more than one sequence, was found when we sequenced AvrLm6-virulent copies (data not shown). One last possibility would be that two copies of AvrLm6 and AvrLm1 are located in tandem in the genome, thus rendering it difficult to identify. The more likely explanation, however, is that, as observed by Irelan and associates (1994) for $N$. crassa, RIP extend beyond the boundaries of duplicated sequences and have mutational effects on neighboring unique sequences. However, in contrast to what was observed by Irelan and associates (1994), no gradient of mutations could be identified from the repeated elements to the AvrLm6 locus and almost the same rate of mutations was found in the different coding and noncoding parts of the gene. This is probably fully attributable to the peculiar genomic context into which both AvrLm1 and AvrLm6 are located because, being surrounded by repeats and being small-sized genes, RIP would act on both sides of the gene and, thus, cause no gradient of degeneration.

Finally, one important point to address in durable management of resistance is not only to understand how new virulences appear but also how (and how fast) they disseminate in natural populations. Here, the data obtained show the occurrence of multiple events leading to virulence, even for a single year of sampling at the same place. For example, for the isolates sampled in Rennes in 2003, deletions, point mutations not attributable to RIP, and diverse RIP mutations were observed. Those results suggest a fast and independent generation of mutations (in particular the ones due to RIP), instead of the diffusion of a particular molecular event in the populations.

Similar events are shown here to contribute to evolution of AvrLm6 and AvrLm1 under Rlm selection pressure. The main difference between the two genes, however, is the diversity of events, including the diversity of RIP-mutated alleles observed for AvrLm6 compared with AvrLm1. The level of polymorphism at the AvrLm6 locus was analyzed at the time when resistance was in the process of being overcome whereas, in the case of AvrLm1, isolates were sampled several years after the resistance was overcome (Gout et al. 2007; Rouxel et al. 2003a). On these bases, it can be hypothesized that the low diversity of events at the AvrLml locus reflects diffusion in population of the most favorable event leading to virulence then reaching, 10 years after the breakdown of AvrLm1, a relative homogeneity at this locus, whereas we are experiencing at the AvrLm6 locus an ongoing process toward the overcoming of the corresponding resistance gene by numerous molecular events leading to virulence. In the coming years, this hypothesis will be evaluated using another recently cloned avirulence gene of L. maculans, AvrLm4-7 (Parlange et al. 2009), which is localized in a genomic context similar to that of AvrLml and AvrLm6, and for which the corresponding resistance gene $R \operatorname{lm} 7$ has been released very recently (2005) in commercial cultivars. This will give us a unique possibility to identify the different molecular events leading to virulence when overcoming a resistance gene in agrosystems, and to study the dynamics of the different virulent alleles in the pathogen populations.

\section{MATERIALS AND METHODS}

\section{Fungal isolates and culture conditions.}

Isolates of L. maculans used in this study were either collected from naturally or experimentally infected plants or ob- tained following in vitro crosses (Table 1). The field populations analyzed were sampled in five locations from France (Versailles, Oucques, Mondonville, Laxou, and Toury) and described by Balesdent and associates (2006) and Gout and associates (2006). Additional reference field isolates were obtained from the IBCN collection maintained at INRA Versailles or from the University of Western Australia collection (UWA isolates). They included the reference isolate BBA62908, one of the oldest European L. maculans isolates available (Rouxel et al. 2003b). They were collected from B. napus or B. oleracea in France, Germany, or Australia. Field isolates enriched in avrlm6 isolates were obtained from different experiments in Rennes or Saint-Florent (France) using a protocol described by Brun and associates (2000), in which the natural inoculum in the fields was increased in avrLm6 isolates by incorporating infected stem residues of Rlm6 genotypes (hereafter, collectively named MX lines) from the previous year's culture, thus mimicking culture conditions with insufficient rotation. A first experiment was performed between 1992 and 1996 in Rennes (Brun et al. 2000; Somda et al. 1999). Isolates termed Rx and MXx were obtained as single ascospores from pseudothecia on MX lines in 1992 or 1993, respectively (Somda et al. 1999). Isolates termed SamRFx were collected from Samourai MX in 1995, the year when Rlm6 was overcome (Brun et al. 2000). A second experiment was performed between 1997 and 2003 in Rennes and Saint-Florent on Eurol MX, Falcon MX, Maxol MX, and S MX. Isolates R1x or C1-2x were collected in 2000 or 2001 in Rennes and Saint Florent from these MX lines. A third experiment was performed from 2002 to 2006 in Rennes using infected residues of Eurol MX. Isolates termed ExF03-X or EF03-x were collected in 2003 on Eurol MX or on the corresponding line lacking $R \operatorname{lm} 6$, Eurol, respectively. The v23.1.3 isolate is a progeny from a cross between two isolates derived from a. 2 and H5, two field isolates collected in France in 1990 and 1989, respectively. The v29.3.1 (avrLm6) isolate is a fourth-generation progeny originating from the same cross, a. 2 $\times$ H5 (Balesdent et al. 2001, 2002). The v23.1.3 isolate of $L$. maculans (AvrLm6) (Balesdent et al. 2001, 2002) has been used for the map-based cloning of AvrLm6 (Attard et al. 2002) followed by a complete sequencing of the corresponding genomic region (Fudal et al. 2007). All fungal cultures were maintained on V8 juice agar medium and highly sporulating cultures were obtained on V8 juice as previously described (Ansan-Melayah et al. 1995).

\section{Plant inoculations.}

The interaction phenotypes (AvrLm6 or avrLm6) of L. maculans isolates were assessed following inoculation with $10^{5}$ conidia on cotyledons of 15-day-old plantlets of B. napus cv. Westar (susceptible control) and one line harboring the Rlm6 resistance gene (Darmor-MX), as previously described (Balesdent et al. 2005).

\section{DNA manipulations.}

For PCR, genomic DNA was extracted from conidia with the DNeasy 96 plant kit (Qiagen S.A., Courtaboeuf, France) as described previously (Attard et al. 2002). Sequences of the primers used to amplify PCR markers during the chromosome walk and for polymorphism studies are available in Supplementary Table S1. PCR amplification was done in a total volume of $15 \mu \mathrm{l}$ containing $0.2 \mu \mathrm{M}$ each dNTP, $1.2 \mu \mathrm{M}$ each primer, 0.6 U of Taq DNA polymerase (Qbiogen, Illkirch, France), $1.5 \mu \mathrm{l}$ of $10 \times$ reaction buffer, and 10 to $30 \mathrm{ng}$ of genomic DNA. PCR amplifications were performed using an Eppendorf Mastercycler EP Gradient thermocycler (Eppendorf, Le Pecq, France). Sequencing was performed using a Beckman Coulter CEQ 8000 automated sequencer (Beckman Coulter, 
Fullerton, CA, U.S.A.) according to the manufacturer's instructions. Procedures for gel electrophoresis, Southern blots, and hybridizations have been reported (Attard et al. 2005).

\section{BAC libraries coverage and screening.}

Construction of the v29.3.1 genomic DNA HindIII BAC library and screening has been described previously (Gout et al. 2006). To allow screening of the BAC libraries by PCR, BAC DNA pools were prepared according to a three-dimensional pooling scheme and BAC DNA was extracted from pooled BAC clones by a boiling-freezing method (Sambrook and Russell 2001). The BAC clones were fully sequenced, finished, and assembled at Genoscope (Evry, France) as described by Gout and associates (2006). Sequence analyses were performed using the Isochore program to compute GC content (available online from the Institut Pasteur), which was set to a sliding window size of 3,500 bp and a shift increment of 100 bp.

\section{Sequence comparisons.}

AvrLm6 virulent and avirulent alleles were aligned using the CLUSTALX program and these aligned sequences were edited using the Genedoc program.

\section{Electrophoretic karyotyping and DNA hybridization.}

Chromosomal DNA was prepared as described by Plummer and Howlett (1993). For SalI digests, agarose plugs of chromosomal DNA were washed four times for $20 \mathrm{~min}$ in distilled water and then incubated in SalI buffer for $30 \mathrm{~min}$ at $4^{\circ} \mathrm{C}$. Plugs were then transferred into fresh SalI buffer containing 20 units of SalI (Invitrogen, Carlsbad, CA, U.S.A.), equilibrated for $30 \mathrm{~min}$ at $4^{\circ} \mathrm{C}$, and then incubated at $37^{\circ} \mathrm{C}$ for $16 \mathrm{~h}$. Plugs were submitted to CHEF electrophoresis on a CHEF DRIII pulsed-field electrophoresis system (Bio-Rad, Hercules, CA, U.S.A.) using $0.5 \times$ Tris-borate EDTA buffer (Sambrook and Russell 2001), with buffer circulation at $10^{\circ} \mathrm{C}$ in $1 \%$ agarose gel (Seakem LE, FMC, Rockland, ME, U.S.A.), with the following conditions: pulse time ramping from 60 to $120 \mathrm{~s}$ for 24 $\mathrm{h}, 6 \mathrm{~V} \mathrm{~cm}^{-1}$, pulse angle $120^{\circ} \mathrm{C}$. Digested fragment sizes were estimated from digital images by comparison with the lambda ladder PFG marker (New England Biolabs, Beverly, MA, U.S.A.). Genomic restricted DNA was vacuum blotted on nylon $\mathrm{N}+$ membranes (Qbiogene, Illkirch, France). Two probes corresponding to the AvrLm6 gene (a 775-bp fragment amplified using primers AvrLm6extU and AvrLm6extL) (Fig. 1) or to LmCys1, a gene present in the same SalI fragment as AvrLm6 and always present in field isolates of L. maculans (a 957-bp fragment amplified using primers LmCys1U and LmCys1L), were used. These DNA fragments were PCR amplified, labeled using the NonaPrimer kit (Qbiogen), and hybridized on the membrane.

\section{ACKNOWLEDGMENTS}

We thank M. Chabirand, L. Coudard, and G. Le Roy (INRA Bioger, Versailles, France) for plant management; and E. Mendes-Pereira and A. Gautier for assistance in sequencing. I. Fudal, S. Ross, and A. L. Besnard were funded by the EU contract QLK5-CT-2002-01813 'SECURE'.

\section{LITERATURE CITED}

Ansan-Melayah, D., Balesdent, M. H., Buée, M., and Rouxel, T. 1995. Genetic characterization of AvrLm1, the first avirulence gene of Leptosphaeria maculans. Phytopathology 85:1525-1529.

Ansan-Melayah, D., Rouxel, T., Bertrandy, J., Letarnec, B., MendesPereira, E., and Balesdent, M. H. 1997. Field efficiency of Brassica napus specific resistance correlates with Leptosphaeria maculans population structure. Eur. J. Plant Pathol. 103:835-841.

Attard, A., Gout, L., Gourgues, M., Kühn, M. L., Schmit, J., Laroche, S.,
Ansan-Melayah, D., Billault, A., Cattolico, L., Balesdent, M. H., and Rouxel, T. 2002. Analysis of molecular markers genetically linked to the Leptosphaeria maculans avirulence gene AvrLm1 in field populations indicates a highly conserved event leading to virulence on RlmI genotypes. Mol. Plant-Microbe Interact. 15:672-682.

Attard, A., Gout, L., Ross, S., Parlange, F., Cattolico, L., Balesdent, M. H., and Rouxel, T. 2005. Truncated and RIP-degenerated copies of the LTR retrotransposon Pholy are clustered in a pericentromeric region of the Leptosphaeria maculans genome. Fungal Genet. Biol. 42:30-41.

Balesdent, M. H., Attard, A., Ansan-Melayah, D., Delourme, R., Renard, M., and Rouxel, T. 2001. Genetic control and host range of avirulence towards Brassica napus cultivars Quinta and Jet Neuf in Leptosphaeria maculans. Phytopathology 91:70-76.

Balesdent, M. H., Attard, A., Kuhn, M. L., and Rouxel, T. 2002. New avirulence genes in the phytopathogenic fungus Leptosphaeria maculans. Phytopathology 92:1122-1133.

Balesdent, M. H., Barbetti, M. J., Li, H., Sivasithamparam, K., Gout, L., and Rouxel, T. 2005. Analysis of Leptosphaeria maculans race structure in a worldwide collection of isolates. Phytopathology 95:10611071.

Balesdent, M. H., Louvard, K., Pinochet, X., and Rouxel, T. 2006. A large scale survey of races of Leptosphaeria maculans occurring on oilseed rape in France. Eur. J. Plant Pathol. 114:53-65.

Brun, H., Levivier, S., Somda, I., Ruer, D., Renard, M., and Chèvre, A. M. 2000. A field method for evaluating the potential durability of new resistance sources: Application to the Leptosphaeria maculans-Brassica napus pathosystem. Phytopathology 90:961-964.

Cambareri, E. B., Jensen, B. C., Schabtach, E., and Selker, E. U. 1989. Repeat-induced G-C to A-T mutations in Neurospora. Science 244:15711575.

Catanzariti, A. M., Dodds, P. N., Lawrence, G. J., Ayliffe, M. A., and Ellis, J. G. 2006. Haustorially expressed secreted proteins from flax rust are highly enriched for avirulence elicitors. Plant Cell 18:243-256.

Chisholm, S. T., Coaker, G., Day, B., and Staskawicz, B. J. 2006. Hostmicrobe interactions: Shaping the evolution of the plant immune response. Cell 124:803-814.

Delourme, R., Pilet-Nayel, M. L., Archipiano, M., Horvais, R., Tanguy, X., Rouxel, T., Brun, H., Renard, M., and Balesdent, M. H. 2004. A cluster of major specific resistance genes to Leptosphaeria maculans in Brassica napus. Phytopathology 94:578-583.

Ellis, J. G., Dodds, P. N., and Lawrence, G. J. 2007. Flax rust resistance gene specificity is based on direct resistance-avirulence protein interactions. Annu. Rev. Phytopathol. 45:289-306.

Farman, M. L., Eto, Y., Nakao, T., Tosa, Y., Nakayashiki, H., Mayama, S., and Leong, S. A. 2002. Analysis of the structure of the AVR1-CO39 avirulence locus in virulent rice-infecting isolates of Magnaporthe grisea. Mol. Plant-Microbe Interact. 15:6-16.

Fitt, B. D. L., Brun, H., Barbetti, M. J., and Rimmer, S. R. 2006. Worldwide importance of Phoma stem canker (Leptosphaeria maculans and L. biglobosa) on oilseed rape (Brassica napus). Eur. J. Plant Pathol. 114:3-15

Flor, H. H. 1942. Inheritance of pathogenicity in Melampsora lini. Phytopathology 32:653-669.

Fudal, I., Bohnert, H. U., Tharreau, D., and Lebrun, M. H. 2005. Transposition of MINE, a composite retrotransposon, in the avirulence gene $A C E 1$ of the rice blast fungus Magnaporthe grisea. Fungal Genet. Biol. 42:761-772.

Fudal, I., Ross, S., Gout, L., Blaise, F., Kuhn, M. L., Eckert, M. R., Cattolico, L., Bernard-Samain, S., Balesdent, M. H., and Rouxel, T. 2007. Heterochromatin-like regions as ecological niches for avirulence genes in the Leptosphaeria maculans genome: Map-based cloning of AvrLm6. Mol. Plant-Microbe Interact. 20:459-470.

Galagan, J. E., and Selker, E. U. 2004. RIP: The evolutionary cost of genome defense. Trends Genet. 20:417-423.

Galagan, J. E., Calvo, S. E., Borkovich, K. A., Selker, E. U., Read, N. D. Jaffe, D., FitzHugh, W., Ma, L. J., Smirnov, S., Purcell, S., Rehman, B., Elkins, T., Engels, R., Wang, S., Nielsen, C. B., Butler, J., Endrizzi, M. Qui, D., Ianakiev, P., Bell-Pedersen, D., Nelson, M. A., WernerWashburne, M., Selitrennikoff, C. P., Kinsey, J. A., Braun, E. L., Zelter, A., Schulte, U., Kothe, G. O., Jedd, G., Mewes, W., Staben, C., Marcotte, E., Greenberg, D., Roy, A., Foley, K., Naylor, J., Stange-Thomann, N., Barrett, R., Gnerre, S., Kamal, M., Kamvysselis, M., Mauceli, E., Bielke, C., Rudd, S., Frishman, D., Krystofova, S., Rasmussen, C., Metzenberg, R. L., Perkins, D. D., Kroken, S., Cogoni, C., Macino, G., Catcheside, D., Li, W., Pratt, R. J., Osmani, S. A., DeSouza, C. P., Glass, L., Orbach, M. J., Berglund, J. A., Voelker, R., Yarden, O., Plamann, M., Seiler, S., Dunlap, J., Radford, A., Aramayo, R., Natvig, D. O., Alex, L. A., Mannhaupt, G., Ebbole, D. J., Freitag, M., Paulsen, I., Sachs, M. S., Lander, E. S., Nusbaum, C., and Birren, B. (2003). The genome sequence of the filamentous fungus Neurospora crassa. Nature 422:859-868. 
Gout, L., Fudal, I., Kuhn, M. L., Blaise, F., Eckert, M., Cattolico, L., Balesdent, M. H., and Rouxel, T. 2006. Lost in the middle of nowhere: The AvrLml avirulence gene of the Dothideomycete Leptosphaeria maculans. Mol. Microbiol. 60:67-80.

Gout, L., Kuhn, M. L., Vincenot, L., Bernard-Samain, S., Cattolico, L., Barbetti, M., Moreno-Rico, O., Balesdent, M. H., and Rouxel, T. 2007. Genome structure impacts molecular evolution at the AvrLm1 avirulence locus of the plant pathogen Leptosphaeria maculans. Environ. Microbiol. 9:2978-2992.

Graia, F., Lespinet, O., Rimbault, B., Dequard-Chablat, M., Coppin, E., and Picard, M. 2001. Genome quality control: RIP (repeat-induced point mutation) comes to Podospora. Mol. Microbiol. 40:586-595.

Hammond-Kosack, K. E., and Parker, J. E. 2003. Deciphering plant-pathogen communication: Fresh perspectives for molecular resistance breeding. Curr. Opin. Biotechnol. 14:177-193.

Idnurm, A., and Howlett, B. J. 2003. Analysis of loss of pathogenicity mutants reveals that repeat-induced point mutations can occur in the Dothideomycete Leptosphaeria maculans. Fungal Genet. Biol. 39:31-37.

Ikeda, K., Nakayashiki, H., Kataoka, T., Tamba, H., Hashimoto, Y., Tosa, Y., and Mayama, S. 2002. Repeat-induced point mutation (RIP) in Magnaporthe grisea: Implications for its sexual cycle in the natural field context. Mol. Microbiol. 45:1355-1364.

Irelan, J. T., Hagemann, A. T., and Selker, E. U. 1994. High frequency repeat-induced point mutation (RIP) is not associated with efficient recombination in Neurospora. Genetics 138:1093-1103.

Jones, J. D., and Dangl, J. L. 2006. The plant immune system. Nature 444:323-329.

Joosten, M. H., Vogelsang, R., Cozijnsen, T. J., Verberne, M. C., and De Wit, P. J. 1997. The biotrophic fungus Cladosporium fulvum circumvents $C f$-4-mediated resistance by producing unstable AVR4 elicitors. Plant Cell 9:367-379.

Kang, S., Lebrun, M. H., Farrall, L., and Valent, B. 2001. Gain of virulence caused by insertion of a Pot 3 transposon in a Magnaporthe grisea avirulence gene. Mol. Plant-Microbe Interact. 14:671-674.

Li, C. X., and Cowling, W. A. 2003. Identification of a single dominant allele for resistance to blackleg in Brassica napus "Surpass 400". Plant Breed. 122:485-488.

Luderer, R., Takken, F. L., de Wit, P. J., and Joosten, M. H. 2002. Cladosporium fulvum overcomes $C f$-2-mediated resistance by producing truncated AVR2 elicitor proteins. Mol. Microbiol. 45:875-884.

Mendes-Pereira, E., Balesdent, M. H., Brun, H., and Rouxel, T. 2003. Molecular phylogeny of the Leptosphaeria maculans-L. biglobosa species complex. Mycol. Res. 107:1287-1304.

Montiel, M. D., Lee, H. A., and Archer, D. B. 2006. Evidence of RIP (repeat-induced point mutation) in transposase sequences of Aspergillus oryzae. Fungal Genet. Biol. 43:439-445.

Orbach, M. J., Farrall, L., Sweigard, J. A., Chumley, F. G., and Valent, B. 2000. A telomeric avirulence gene determines efficacy for the rice blast resistance gene Pi-ta. Plant Cell 12:2019-2032.

Parlange, F., Daverdin ,G., Fudal, I., Kuhn, M. L., Balesdent, M. H., Blaise, F., Grezes-Besset, B., and Rouxel, T. 2009. Leptosphaeria maculans avirulence gene AvrLm4-7 confers a dual recognition specificity by $R \operatorname{lm} 4$ and $R \operatorname{lm} 7$ resistance genes of oilseed rape, and circumvents $R \operatorname{lm} 4$-mediated recognition through a single amino acid change. Mol. Microbiol. 71:851-863

Plummer, K. M. and Howlett, B. J. 1993. Major chromosomal length polymorphisms are evident after meiosis in the blackleg fungus, Leptosphaeria maculans. Curr. Genet. 24:107-113.

Rehmany, A. P., Gordon, A., Rose, L. E., Allen, R. L., Armstrong, M. R.,
Whisson, S. C., Kamoun, S., Tyler, B. M., Birch, P. R. J., and Beynon, J. L. 2005. Differential recognition of highly divergent downy mildew avirulence gene alleles by $R P P 1$ resistance genes from two Arabidopsis lines. Plant Cell 17:1839-1850.

Rep, M., van der Does, H. C., Meijer, M., van Wijk, R., Houterman, P. M., Dekker, H. L., de Koster, C. G., and Cornelissen, B. J. 2004. A small, cysteine-rich protein secreted by Fusarium oxysporum during colonization of xylem vessels is required for $I-3$-mediated resistance in tomato. Mol. Microbiol. 53:1373-1383.

Ridout, C. J., Skamnioti, P., Porritt, O., Sacristan, S., Jones, J. D., and Brown, J. K. 2006. Multiple avirulence paralogues in cereal powdery mildew fungi may contribute to parasite fitness and defeat of plant resistance. Plant Cell 18:2402-2414.

Rouxel, T., and Balesdent, M. H. 2005. The stem canker (blackleg) fungus, Leptosphaeria maculans, enters the genomic era. Mol. Plant Pathol. 6:225-241.

Rouxel, T., Penaud, A., Pinochet, X., Brun, H., Gout, L., Delourme, R., Schmit, J., and Balesdent, M. H. 2003a. A 10-year survey of populations of Leptosphaeria maculans in France indicates a rapid adaptation towards the Rlm1 resistance gene of oilseed rape. Eur. J. Plant Pathol. 109:871-881.

Rouxel, T., Willner, E., Coudard, L., and Balesdent, M. H. 2003b. Screening and identification of resistance to Leptosphaeria maculans (stem canker) in Brassica napus accessions. Euphytica 133:219-231.

Sacristan, S., and Garcia-Arenal, F. (2008). The evolution of virulence and pathogenicity in plant pathogen populations. Mol. Plant Pathol. 9:369384.

Sambrook, J., and Russell, D. W. 2001. Molecular Cloning: A Laboratory Manual. Cold Spring Harbor Laboratory Press, Cold Spring Harbor, NY, U.S.A.

Schurch, S., Linde, C. C., Knogge, W., Jackson, L. F., and McDonald, B. A. 2004. Molecular population genetic analysis differentiates two virulence mechanisms of the fungal avirulence gene NIP1. Mol. PlantMicrobe Interact. 17:1114-1125.

Somda, I., Delourme, R., Renard, M., and Brun, H. 1999. Pathogenicity of Leptosphaeria maculans isolates on a Brassica napus-B. juncea recombinant line. Phytopathology 89:169-175.

Stergiopoulos, I., De Kock, M. J., Lindhout, P., and De Wit, P. J. (2007). Allelic variation in the effector genes of the tomato pathogen Cladosporium fulvum reveals different modes of adaptive evolution. Mol. PlantMicrobe Interact. 20:1271-1283.

Watters, M. K., Randall, T. A., Margolin, B. S., Selker, E. U., and Stadler, D. R. 1999. Action of repeat-induced point mutation on both strands of a duplex and on tandem duplications of various sizes in Neurospora. Genetics 153:705-714.

Westerink, N., Brandwagt, B. F., de Wit, P. J., and Joosten, M. H. 2004 Cladosporium fulvum circumvents the second functional resistance gene homologue at the $C f-4$ locus $(H c r 9-4 E)$ by secretion of a stable avr4E isoform. Mol. Microbiol. 54:533-545.

Zhou, E., Jia, Y., Singh, P., Correll, J. C., and Lee, F. N. 2007. Instability of the Magnaporthe oryzae avirulence gene AVR-Pita alters virulence. Fungal Genet. Biol. 44:1024-1034.

Zipfel, C., and Felix, G. (2005). Plants and animals: A different taste for microbes? Curr. Opin. Plant Biol. 8:353-360.

\section{AUTHOR-RECOMMENDED INTERNET RESOURCES}

CLUSTALX program: bips.u-strasbg.fr/fr/Documentation/ClustalX GeneDoc program: www.nrbsc.org/gfx/genedoc/index.html 